Original Research Article

\title{
Evaluation of eye prescriptions for appropriateness and rationality in indoor patients: an observational prospective study
}

\author{
Andrew Mark ${ }^{1}$, Sagun Desai ${ }^{2}$
}

Department of Pharmacology, ${ }^{1}$ Dr. M.K. Shah Medical College and Research centre, Ahmedabad, ${ }^{2}$ SBKS Medical Institute and Research Centre, Waghodia, Gujarat, India

Received: 18 June 2019

Accepted: 31 July 2019

\section{*Correspondence to:}

Dr. Andrew Mark,

Email: drandrew81@gmail.com

Copyright: (C) the author(s), publisher and licensee Medip Academy. This is an openaccess article distributed under the terms of the Creative Commons Attribution NonCommercial License, which permits unrestricted noncommercial use, distribution, and reproduction in any medium, provided the original work is properly cited.

\begin{abstract}
Background: In the branch of ophthalmology, there have been many developments of new ocular therapeutic agents. Indiscriminate use of topical drugs can lead to various unwanted effects. In order to improve drugs therapeutic efficacy, minimize adverse effects, and delay development of resistance, drug utilization trends and patterns need to be evaluated periodically. The objective of the study was to evaluate drug utilization pattern, appropriateness of use and rationality in indoor patients attending ophthalmology department.

Methods: A prospective, observational study was conducted over a period of 15 months in the Ophthalmology Department of Tertiary care teaching Hospital after obtaining permission from IEC. Information of patients collected included age, sex, duration of stay, diagnosis, income per capita per month, information about drugs given- their dose, frequency, route and duration were recorded from the day of admission till discharge.

Results: A total of 150 patients were enrolled in the study with M:F was 1.43:1. Mean hospitalization was 3.00 \pm 1.17 days. Most common disease were cataract $(108,72 \%)$ followed by pterygium $(15,10 \%)$. Mean of $16.35 \pm 4.25$ medicines were prescribed. On most occasions $(2274,92.70 \%)$ the medicines were prescribed using brand names. Injection gentamicin 147 (98\%) and flurbiprofen eye drops 145 (96.67\%) were the most common drugs used. Majority (83.20\%) of medicines were rational. Out of 125 medicines, 35 (28\%) were FDC and 90 $(72 \%)$ were single ingredient. All 100\% medicine uses were appropriate with respect to dosage form, route of administration, dosage, frequency of administration and duration of therapy.

Conclusions: Polypharmacy is common practice in eye department which increases inappropriateness and irrational use.
\end{abstract}

Keywords: Drug utilization study, Ophthalmology, Rational

\section{INTRODUCTION}

Drug utilization was defined by the World Health Organization (WHO) in 1977 as "the marketing, distribution, prescription and use of drugs in a society, with special emphasis on the resulting medical, social, and economic consequence". ${ }^{1}$

Numerous prescription and nonprescription medications, both topical and systemic, may alter the quantity or the quality of vision and pose a threat to eye health. An integral component of healthy sight counseling is a thorough health history, with special attention focused on medication use. Considering the vast array of drugs commonly being taken, either alone or in combination, and the potential for vision and eye-related sequelae, it may not be possible for eye care practitioners to be familiar with all the potential ocular side effects of every drug. It is, however, clinically relevant to maintain the awareness that drugs can affect vision and eye health and to foster a high index of suspicion about the potential role of medications in contributing to unusual visual or ocular 
complaints. ${ }^{2}$ For achieving the goals of pharmacotherapy, it is essential that drugs are selected and used appropriately while producing no or at the best minimal adverse effects. ${ }^{3}$

To the best of our knowledge, there is paucity of data in this area of drug utilization study in ophthalmic disorders. We did not find many studies of this nature carried out in India, Gujarat in particular. Hence we thought it would be prudent to carry out the study of drug utilization pattern in in-patients of Ophthalmology department. If such a study is conducted, we can identify drug utilization pattern and the appropriateness of use of selected drugs along with dosage, frequency, duration of treatment, route of administration, ADRs to drug therapy with their nature and the final outcome of the patient.

Hence we undertook the present study to gather the relevant data on drug utilization in patients admitted to ophthalmology department of tertiary care teaching Hospital in rural Gujarat.

\section{Objectives}

- To study the drug utilization pattern in various conditions in indoor patients of ophthalmology.

- To find out appropriateness of prescription according to standard treatment guidelines.

- To determine the rationality of medicines of their use.

\section{METHODS}

A prospective, observational study was conducted for a duration of 15 months in tertiary care teaching hospital in Gujarat. Prior permission of Institutional Ethics committee was taken. Written Informed consent after explaining the subjects in the vernacular language. All the patients admitted in the Ophthalmology ward and patients willing to participate in the study were included. All demographic, clinical characteristics, prescription details were noted in the case record form till the patient discharge.

Data were organized in a manner so as to derive the following information (i) age groups of patients (ii) income groups (iii) pattern of diseases (iv) profile of medicine/s used (v) essentiality and rationality status of medicines used (v) appropriateness of medicine use with respect to dosage form, route of medicine administration, dose, frequency of administration and duration of use (vii) cost of medicine therapy etc. No observations were offered on the diagnosis made by treating doctors and on management of patients, including selection of medicines. Medicines which are included in the $18^{\text {th }}$ model list of essential medicines of WHO, 2013 were considered as essential (E). ${ }^{4}$ Medicines not appearing in the list but similar to medicines of same therapeutic class in the list were considered as substituted essential (SE).
Rests of the medicines were considered as non-essential (NE).

Appropriateness of use of medicines was assessed using a structured 0-20 point arbitrary appropriateness scale. Score of 0-13 was considered as Inappropriate, 14-17 was appropriate and 18-20 was considered as most appropriate.

Prescriptions containing evidenced based indications were considered as rational and rests of the medicines were labelled as irrational (IR).

\section{Statistical analysis}

Data were analyzed and appropriate statistical methods like Chi-square test, population test or t-test were employed to analyze data throughout the study. $\mathrm{P}$ values equal to or less than 0.05 were considered as significant.

\section{RESULTS}

\section{Demographic details}

A total 150 patients were included in this prospective study and it was carried out by visiting and examining the patients from the day of admission till discharge from the hospital during stipulated study period of one year and three months. The age ranged from 18 years to 70 years with a mean of $57.15 \pm 12.65($ Mean \pm SD) years (Table 1). Majority 72 (48\%) of patients were in the age group of 50 years to less than 65 years, followed by 44 (29.33\%) in more than 65 years of age group (Figure 1).

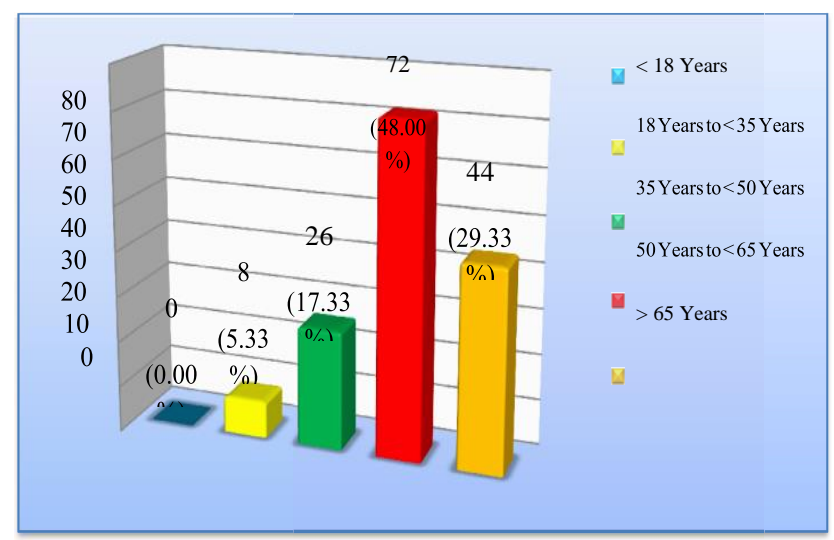

Figure 1: Age-wise distribution of patients $(n=150)$.

Table 1: Age of patients in years $(n=150)$

\begin{tabular}{|lll|}
\hline Age $($ years) & Number $(\mathbf{N})$ & Percentage $(\%)$ \\
\hline$<\mathbf{1 8}$ & 0 & 0.00 \\
\hline $\mathbf{1 8}$ to $<\mathbf{3 5}$ & 8 & 5.33 \\
\hline $\mathbf{3 5}$ to $<\mathbf{5 0}$ & 26 & 17.33 \\
\hline $\mathbf{5 0}$ to $<\mathbf{6 5}$ & 72 & 48.00 \\
\hline$>\mathbf{6 5}$ & 44 & 29.33 \\
\hline
\end{tabular}




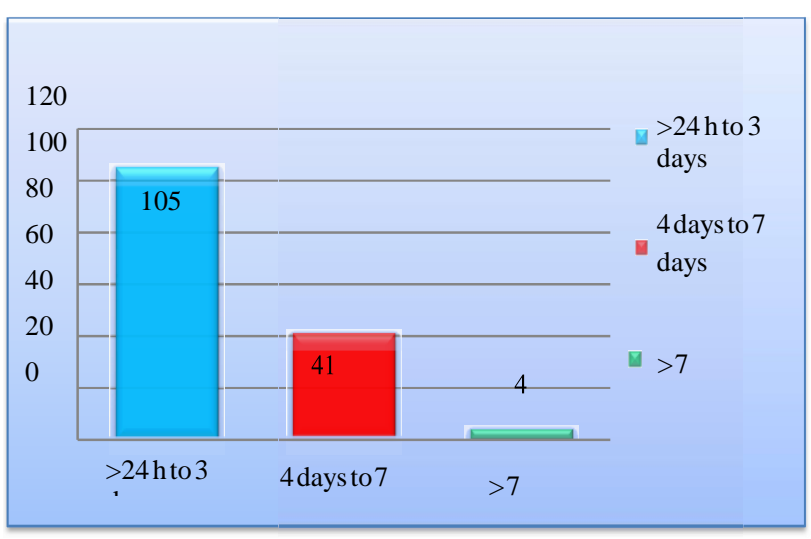

Figure 2: Hospital stay of patients in days $(\mathrm{n}=150)$.

Table 2: Types of medicines used in patients $(n=125)$.

\begin{tabular}{|lll|}
\hline Name of medicine & No. of patient & $\%$ \\
\hline Inj. Dexamethasone & 147 & 98.00 \\
\hline Flurbiprofen eds & 145 & 96.67 \\
\hline T. Ranitidine & 132 & 88.00 \\
\hline Inj. Gentamicin & 132 & 88.00 \\
\hline T. Ciprofloxacin & 130 & 86.67 \\
\hline Inj. Hyaluronidase & 130 & 86.67 \\
\hline T. Ibuprofen & 129 & 86.00 \\
\hline Povidone Iodine eds & 129 & 86.00 \\
\hline Cyclopentolate eds & 128 & 85.33 \\
\hline Ciprofloxacin eds & 112 & 74.67 \\
\hline
\end{tabular}

\section{Patient characteristics}

Average duration of stay in the hospital was $3.00 \pm 1.17$ days with minimum duration being 2 days and maximum being 9 (Figure 2). Seventy percent of patients (105) required to stay for up to 3 days in the hospital and 41
(27.33\%) spent 4 to 7 days in the hospital. Only 4 (2.67\%) patients were in the hospital for more than 7 days.

\section{Co-morbid conditions}

Of the 150 patients, majority $(108,72 \%)$ of them had cataract; $42(28 \%)$ patients had cataract in both the eyes and 66 (44\%) had cataract in one eye. Pterygium was the next common ocular condition. Fifteen (10\%) patients had pterygium of whom $4(2.67 \%)$ had in both eyes and 11 (7.33\%) in one eye. Rest of the patients accounted for less than $2 \%$ for each of the conditions.

\section{Prescription pattern}

All 150 patients were prescribed average 16.35 medicines, culminating into a total of 2453 medicine uses. Of these, majority of the medicines were prescribed using brand names $(2274,92.70 \%)$. Only $179(7.30 \%)$ medicines were prescribed by their official (International nonproprietary names or generic) names.

Each patient received minimum 1 to 12 medicines on some day of hospital stay and maximum 1 to 28 on some day during their hospital stay. This worked out to be $3.45 \pm 2.44$ minimum numbers of medicines and $9.21 \pm 3.76$ as maximum number of medicines on some day during hospital stay. On an average, each patient received $6.58 \pm 2.65$ medicines on each day of their hospital stay. Overall, only 125 medicine formulations were used in all participants. Each patient on an average had received $16.35 \pm 4.25$ medicines from these 125 formulations.

The most commonly prescribed medicines included Inj. Dexamethasone (147, 98.00\%), Flurbiprofen eds (145, 96.67\%). Followed by T. Ranitidine (132, 88.00\%), Inj. Gentamicin (132, 88.00\%), T. Ciprofloxacin (130, $86.67 \%)$, Inj. Hyaluronidase (130, 86.67\%), T. Ibuprofen $(129,86.00 \%)$, Povidone iodine eds $(129,86.00 \%)$ and Cyclopentolate eds $(128,85.33 \%)$ (Table 2).

Table 3: Essentiality and rationality status of FDCs used ( $n=35)$.

\begin{tabular}{|c|c|c|c|c|}
\hline Composition & Essentiality & Rationality & $\mathbf{N}$ & $\%$ \\
\hline Tropicamide + phenylephrine eds & $\mathrm{NE}$ & $\mathrm{R}$ & 107 & 71.33 \\
\hline $\mathrm{NaCl}, \mathrm{KCl}, \mathrm{CaCl}_{2}, \mathrm{MgCl}_{2}, \mathrm{C}_{2} \mathrm{H}_{3} \mathrm{NaO}_{2}, \mathrm{C}_{6} \mathrm{H}_{5} \mathrm{Na}_{3} \mathrm{O}_{7}$ & NE & $\mathrm{R}$ & 67 & 44.67 \\
\hline Gatifloxacin + dexamethasone eds & $\mathrm{NE}$ & IR & 63 & 42.00 \\
\hline $\mathrm{NaCl}, \mathrm{C}_{3} \mathrm{H}_{5} \mathrm{NaO}_{3}, \mathrm{KCl}, \mathrm{CaCl}_{2} .2 \mathrm{H}_{2} \mathrm{O}$ & $\mathrm{NE}$ & $\mathrm{R}$ & 60 & 40 \\
\hline $\begin{array}{l}\text { Hypromellose, } \mathrm{NaCl}, \mathrm{KCl} \text {, magnesium chloride hexahydrate, } \\
\text { sodium acetate, sodium citrate dihydrate e/o }\end{array}$ & $\mathrm{NE}$ & $\mathrm{R}$ & 23 & 15.33 \\
\hline Ofloxacin + prednisolone eds & $\mathrm{NE}$ & IR & 17 & 11.33 \\
\hline Multi-vitamin & $\mathrm{NE}$ & IR & 11 & 7.33 \\
\hline T. ascorbic acid+ sodium ascorbate & $\mathrm{NE}$ & $\mathrm{R}$ & 10 & 6.67 \\
\hline Ibuprofen + PCM & NE & IR & 6 & 4 \\
\hline Calcium + Vit D3 & $\mathrm{NE}$ & $\mathrm{R}$ & 5 & 3.33 \\
\hline Diclofenac+PCM & NE & IR & 4 & 2.67 \\
\hline Moxifloxacin + ketorolac tromethamine eds & NE & IR & 60 & 40.00 \\
\hline
\end{tabular}


Of the total 125 medicines used, $44(35.20 \%)$ were those which are listed in the 18th model list of essential medicines (WHO, 2013). Additional 25 (20.00\%) medicines qualified to be designated as substituted essential medicines. Remaining $56(44.80 \%)$ medicines were found to be nonessential medicines.

Out of 2453, 1143 (46.60\%), 477 (19.45\%) and 833 $(33.96 \%)$ medicine uses were by essential, substituted essential and nonessential medicines respectively. Use of rational medicines was in $2258(92.05 \%)$ medicine uses leaving only $195(7.95 \%)$ as by irrational (IR) medicines.

Most commonly used essential and rational medicines were dexamethasone and gentamicin which were used in $147(98.00 \%)$ and $132(88.00 \%)$ patients respectively (Table 3). Most commonly used substituted essential and rational medicines were flurbiprofen and povidone iodine. They were used in 145 (96.67\%) and 129 (86.00\%) patients respectively. Most commonly used nonessential and irrational medicine was gatifloxacin+ dexomethasone and it was used in $63(42.00 \%)$ patients.

Of the 125 medicines used, $35(28 \%)$ medicines were FDCs, from which only $1(2.86 \%)$ FDC, is listed in essential medicine list of WHO, 2013. This only essential FDC is tablet amoxicillin + clavulanic acid. Remaining 34 $(97.14 \%)$ were considered as nonessential FDCs. However 18 (51.43\%) FDCs were considered rational on the basis of WHO criteria. Remaining 17 (48.57\%) were considered irrational.

Table 4: Appropriateness of duration of therapy $(n=2453)$.

\begin{tabular}{|llll|}
\hline Score & Status & Number $(\mathbf{N})$ & $\%$ \\
\hline $\mathbf{5}$ & Most appropriate & 2453 & 100 \\
\hline $\mathbf{3}$ & Appropriate & - & - \\
\hline $\mathbf{0}$ & Inappropriate & - & - \\
\hline & Total & 2453 & 100 \\
\hline
\end{tabular}

In all $2453(100 \%)$ medicine uses the dosage form, route of administration of medicine, dosage, frequency of administration and duration of therapy were found to be appropriate or most appropriate (Table 4).

\section{Pharmacoeconomics}

Overall cost of medicine therapy in all patients ranged from Rs. 110 to Rs.1338.50 with a mean of $644.20 \pm 205.13$. The daily cost of medicine therapy for all patients ranged from Rs. 27.50 to Rs. 533.75/- with a mean of Rs. $201.31 \pm 78.40$.

Cost ratio analysis showed that of the total 77 medicines used exclusively for ophthalmic purpose, 18 (23.38\%) medicines were the costliest alternatives (cost ratio up to 1.00) whereas in remaining $59(76.62 \%)$ cases, cheaper alternatives (cost ratio more than 1.00) were used.
Similarly in $23(29.87 \%)$ cases, the prescribed brands were the cheapest alternatives (cost ratio up to 1.00) whereas for remaining $54(70.13 \%)$ medicines, costlier alternatives (cost ratio more than 1.00) were used.

\section{DISCUSSION}

Present study was carried out with a view to investigate various aspects of drug utilization in patients getting admitted to the ophthalmology ward of a tertiary care teaching rural hospital.

Despite our extensive search on net we could find only one study carried out in the patients admitted to eye ward and only five studies carried out in patients attending to the outdoor ophthalmic department. ${ }^{5-9}$ Moreover, these studies had focussed only on limited aspects of drug utilization. None of them had studied aspects like essentiality and rationality of medicines used including that of FDCs, appropriateness in use of medicines.

The ratio of male patients to female patients was 1.24:1, clearly showing a preponderance of males over females. This could probably be due to two factors: (i) a typical male dominated society as part of Indian culture, especially in middle and lower middle classes in rural area and (ii) a male, by and large, is a bread earner in the family and therefore may get more attention than others. ${ }^{10,11}$ However, Gangwar et al, in a similar study, found male to female patient ratio of 1.1:1 showing lesser preponderance of males than in our study. ${ }^{5}$

Age presentation was similar to that of Gangwar et al who also found that $77.20 \%$ of their patients admitted to ophthalmology ward were between the age of 45 years and 75 years. ${ }^{5}$ The mean age of our 150 patients was $57.15 \pm 12.65$ years. As such eye problems are more common in elderly and older adults than in children and younger adults.

In the recent time due to advances in medical technology, particularly in the field of ophthalmology, the hospital stay of patients has been significantly reduced. In the present study also we found that the average stay of the patient in the hospital for ophthalmic conditions was $3.00 \pm 1.17$ days with a range from 2 days to 9 days.

In our study most common condition was cataract followed by pterygium which was similar to the study of Gangwar et al but second most common cause was glaucoma in his study.

Use of multiple medicines is common problem in India, both in office practice and hospitalized patients. ${ }^{12} \mathrm{We}$ found that $110(73.33 \%)$ patients out of 150 patients had received more than five medicines. This kind of polypharmacy, that too in a tertiary care teaching hospital, must be viewed seriously. Several factors may have attributed to the practice of polypharmacy. Be it as it may, polypharmacy has many disadvantages and may go 
against the patient interest. Therefore conscious efforts should be made to minimize the practice of polypharmacy. Prescription audit and insistence on evidence based practice can help in this direction.

Gangwar et al found that the most common medicines prescribed to their IPD patients were local anaesthetics followed by anti-inflammatory (paracetamol) and antibiotics+steroids eye drops (tobramycin+ dexamethasone). But in our study it was dexamethasone, flurbiprofen, gentamicin and ranitidine which was prescribed for GI prophylaxis. ${ }^{5}$

It is not enough to select appropriate medicines for treating patients. It is equally important to use the selected medicines in an appropriate manner with regard to dosage form, route of administration, dose, frequency of administration and duration of therapy. As the investigators of the present study did not have adequate training or competence in the field of ophthalmology, the diagnosis made by the staff of ophthalmology department and selection of medicines made for treatment were accepted as final. However, the appropriateness of use of selected medicines was analyzed using a structured scoring system. We found that once selected, all medicines were used appropriately or most appropriately, securing maximum allocated points, for all $2453(100 \%)$ prescription encounters.

The present study has several positive features and a few limitations.

The positive features of the study include: (i) the study was carried out for the first time in our institution and only one of the scanty studies of this nature in Gujarat and India; (ii) the study included the investigation of several parameters, otherwise not included in other studies found on literature search. The aspects which were studied probably for the first time were (a) selection of essential and rational medicines and the extent of their use in patients; (b) measuring the appropriateness of various facets of medicine use by using a structured 20 point scale; (c) scenario of using the FDCs in relation to their rationality and essentiality; (d) cost comparison of medicines used and cost analysis of medicine therapy in relation to economic class of the patients; (e) attempt to identify the ADR of medicines used and details thereof (iii) the outcome of this study may provide some useful guidelines for making the medicine therapy more rational and cost effective without compromising with quality of the care; (iv) attempt was made to compare the findings of this study with those of similar studies.

On the other hand, the present study had a few limitations as under: (i) this was only an observational cross sectional study wherein a randomized clinical trial was not possible because of reasons of ethics; (ii) the study was relatively for a shorter period, allocating only 15 months to recruit the participants in the study.

\section{CONCLUSION}

Most commonly used essential and rational medicines were dexamethasone and gentamicin. Polypharmacy is defined as the use of five or more regular medications. Polypharmacy is common practice in eye department which increases inappropriateness and irrational use.

\section{ACKNOWLEDGEMENTS}

My sincere thanks are to Dr. G. V. Shah Dean, S. B. K. S. Medical College, Sumandeep Vidyapeeth, for giving the permission to carry out this work and also for pepping up my morale throughout the study.

Funding: No funding sources

Conflict of interest: None declared

Ethical approval: The study was approved by the Institutional Ethics Committee

\section{REFERENCES}

1. The selection of essential drugs: report of a WHO expert committee. World Health Organ Tech Rep Ser. 1977;(615):1-36.

2. Sachdeva P D, Patel B G. Drug Utilization StudiesScope And Future Perspectives. Int J Pharma Biological Res. 2010;1(1):11-7.

3. Jaanus SD. Ocular effects associated with medications. Available at: trade.transitions.com/ direct/10169. Accessed on 28 September 2012.

4. World Health Organization. WHO model list of essential medicines. Available at: http://apps.who. int/iris/bitstream/10665/93142/1/EML_18_eng.pdf?u $\mathrm{a}=1$. Accessed on 18 August 2014.

5. Gangwar A, Singh R, Singh S, Sharma BD. Pharmacoepidemiology of drugs utilized in ophthalmic outpatient and inpatient department of a tertiary care hospital. J Applied Pharma Sci. 2011;1(9):135-140.

6. Prajwal P, Rai M, Gopalakrishna HN, Kateel R. An Exploratory Study on the Drug Utilization Pattern in Glaucoma patients at a Tertiary Care Hospital. J Applied Pharma Sci. 2013;3(10):151-5.

7. Maniyar Y, Bhixavatimath P, Akkone V. A drug utilization study in the ophthalmology department of a Medical College, Karnataka, India. J Clin Diagnos Res. 2011;5(1):82-4.

8. Jadhav PR, Moghe VV, Deshmukh YA. Drug Utilization Study in Ophthalmology Outpatients at a Tertiary Care Teaching Hospital. ISRN Pharmacology. 2013.

9. Jain VK, Shrivastava B, Agarwal M. Drug utilization pattern of drugs used along ophthalmic antiallergics formulations used in patients diagnosed with seasonal and perennial allergic conjunctivitis. AJPSR. 2011;1(5):15-20.

10. Ahmed QS, Sayedda K, Agarwal A, Ansari NA. Drug utilization study of antiglaucoma drugs in a 
tertiary care teaching hospital, Bareilly. World J Pharm Res. 2014;3(2):2420-8.

11. Chakraborty P, Chakraborty L, Karmakar K, Kapila S. Taxation and Gender Equity: A Comparative Analysis of Direct and Indirect taxes in developing and developed countries. London and New York: Routledge; 2010: 107-117.
12. Rambhade S, Chakarborty AN. A Survey on Polypharmacy and Use of Inappropriate Medications. Toxicol Int. 2013;19(1):68-73.

Cite this article as: Mark A, Desai S. Evaluation of eye prescriptions for appropriateness and rationality in indoor patients: an observational prospective study. Int J Basic Clin Pharmacol 2019;8:2054-9. 